\title{
INFLUENCE OF GRINDING PARAMETERS ON FORCES WHEN Grinding MARAging STEEL X3NiCOMO 1895 WITH SiC GRINDING WHEELS
}

\author{
Jindřich Farský, Tomáš Bakša, Miroslav Zetek
}
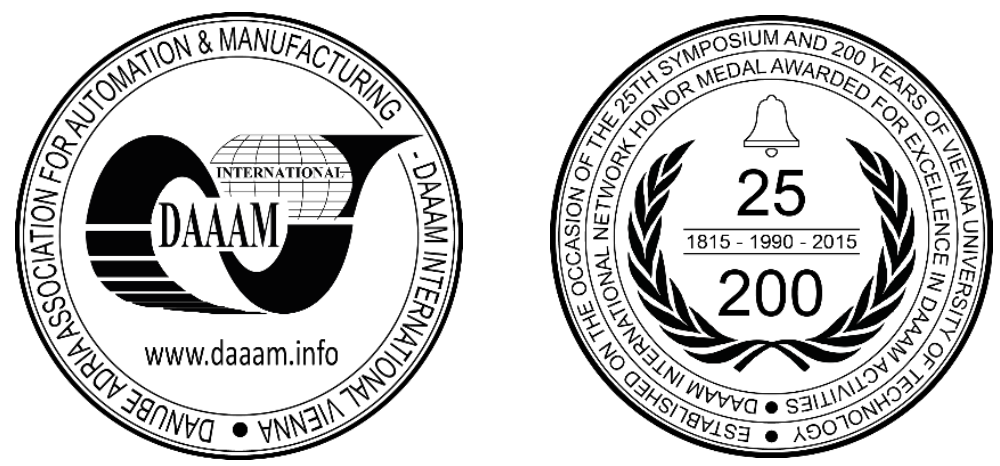

This Publication has to be referred as: Farsky, J[indrich]; Baksa, T[omas] \& Zetek, M[iroslav] (2018). Influence of Grinding Parameters on Forces when Grinding Maraging Steel X3Nicomo 1895 with SiC Grinding Wheels, Proceedings of the 29th DAAAM International Symposium, pp.0767-0771, B. Katalinic (Ed.), Published by DAAAM International, ISBN 978-3-902734-20-4, ISSN 1726-9679, Vienna, Austria

DOI: $10.2507 / 29$ th.daaam.proceedings.111

\begin{abstract}
This work deals with the influence of the grinding parameters on the forces when grinding maraging steel X3NiCoMo 18 95 using SiC grinding wheels. This steel is used for mechanically stressed tools, for which it is necessary to select a material with a high strength limit and yield strength and which must also be toughness and have low sensitivity to any notching at elevated temperatures. The aim of this work is to measure the grinding forces which arise when grinding the steel which can influence the surface and the size of wear of the grinding wheel.
\end{abstract}

Keywords: grinding; SiC; forces; grinding wheel; load

\section{Introduction}

The size of the grinding force can change during grinding. The change of the grinding force depends on the grinding parameters and other variables such as the kind of grinding wheels used, the type of cooling liquid, the material which is to be ground, and so on. The size of the grinding forces can be influenced by the surface quality, the residual stress and the grinding tool. [1], [2], [3]

The grinding conditions can influence the grinding forces which can increase and be dangerous for the future component, or can be lower and be safe. In addition, they affect all these variables. Therefore, setting up the correct grinding parameters is very important. These parameters are the grinding speed, feed rate, axial feed rate, radial feed rate and the amount of material taken per unit of time. Their influences are shown in

Fig. 1, which describes the influence of the grinding parameters on the forces. Changing the grinding parameters can have a positive influence. [4], [5], [6]

The aim of this work is to investigate the influence of the grinding conditions on the forces when grinding maraging steel X3NiCoMo 1895 . The changes and values of the forces are very important for the grinding process because they can influence the resulting component and the amount of wear on the grinding wheel. [7], [8] 


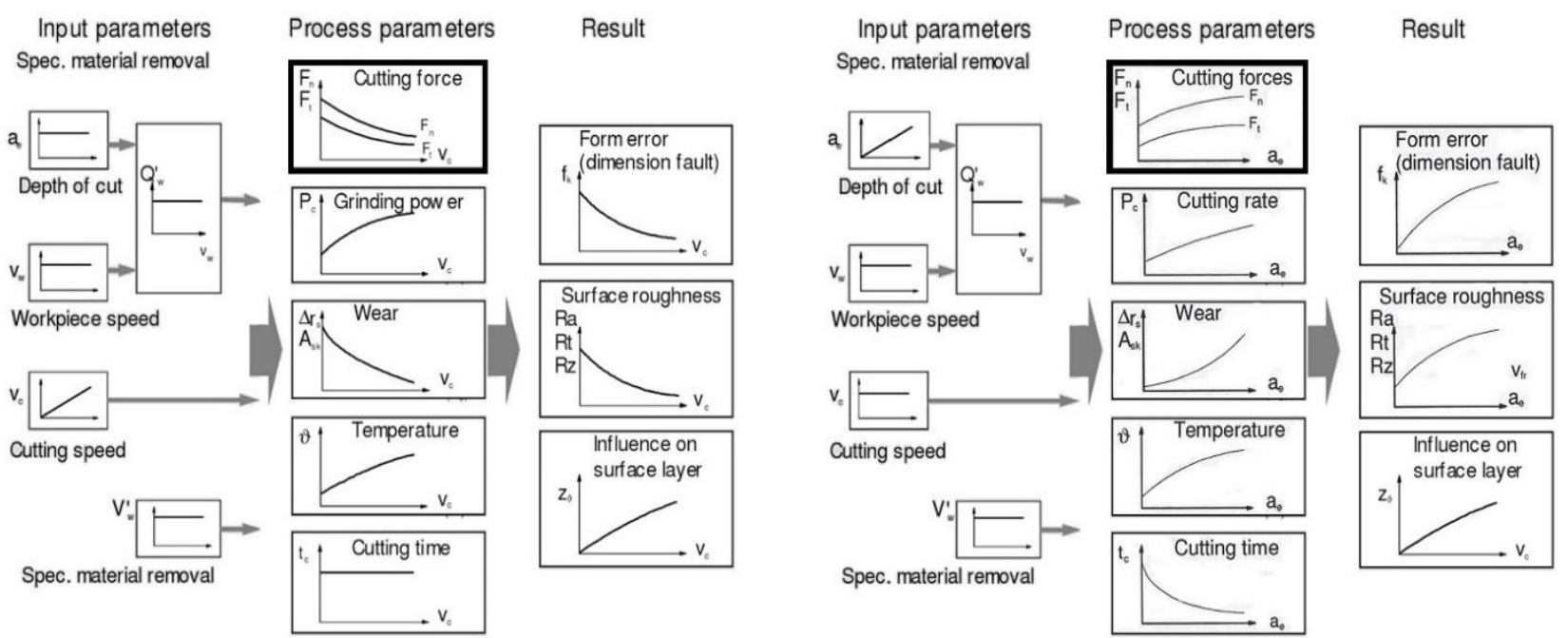

Fig. 1. Influence of grinding conditions on the values of forces [1]

\section{Material}

The maraging steel which was ground is DIN X3NiCoMo 189 5. It is a high strength martensitic curable steel with an optimal combination of very high tensile strength and toughness. The chemical composition of this material is shown in Table 1. The material is supplied in the annealed state with a hardness of $350 \mathrm{HV}$. This material is used in mechanically stressed tools. Typically, it is used in forms for cold forming, pressure die-casting, separators, and so on. Its mechanical properties are shown in Table 2. [9]

$\begin{array}{cccccc}\mathbf{C} & \text { Co } & \text { Mo } & \text { Ni } & \text { Ti } & \text { Other } \\ <0.03 \% & 9.0 \% & 5.0 \% & 18.5 \% & 0.75 \% & \mathrm{Al}, \mathrm{B}, \mathrm{Zr}\end{array}$

Table 1. Chemical composition of maraging steel X3NiCoMo 1895 [9]

$\begin{array}{cccccc}\text { Yield strength } & \begin{array}{c}\text { Tensile } \\ \text { strength }\end{array} & \text { Ductility } & \text { Contraction } & \begin{array}{c}\text { Notch } \\ \text { toughness }\end{array} & \text { Hardness } \\ 640 \mathrm{MPa} & 930-1130 \mathrm{MPa} & 12 \% & 60 \% & 55 \mathrm{~J} & 350 \mathrm{HV}\end{array}$

Table 2. Mechanical properties of maraging steel X3NiCoMo 1895 in annealed condition [9]

\section{Experiment}

The experiment measured the forces when grinding with variable grinding conditions. The experiment was done on a CNC tool grinding machine, the ANCA MX7, with two different conventional grinding wheels. The first grinding wheel used is labelled $\mathrm{SiC}-01$ and the second grinding wheel is $\mathrm{SiC}-02$. Their specifications are shown in Table 3. Before each experiment the grinding wheels were recovering with corundum grinding stones.

\begin{tabular}{|c|c|c|c|c|c|c|c|}
\hline Designation & Specification & Shape & Dimension & Type of grain & $\begin{array}{c}\text { Grain size } \\
\text { [FEPA] }\end{array}$ & Bonding & Hardness \\
\hline SiC-01 & $\begin{array}{c}49 \mathrm{C} 220 \mathrm{~K} 9 \\
\mathrm{~V} 40\end{array}$ & $1 \mathrm{~A} 1$ & $100 \times 6$ & $\begin{array}{l}\text { Silicon } \\
\text { carbide green }\end{array}$ & 220 (very soft) & Ceramic & Medium \\
\hline SiC-02 & SC $80-8-\mathrm{V}$ & $1 \mathrm{~A} 1$ & $117 \times 10$ & $\begin{array}{c}\text { Silicon } \\
\text { carbide green }\end{array}$ & 80 (soft) & Ceramic & Hard \\
\hline
\end{tabular}

Table 3. Specification of Grinding wheels

The test specimens are a flat stick shape, which must be clamped in a special clamping rig, which has a cylindrical part for clamping to the machine, as shown in Fig. 2. The basic dimensions of the test specimens are $36 \times 5.2 \times 180 \mathrm{~mm}$ (height $\mathrm{x}$ width $\mathrm{x}$ length). 


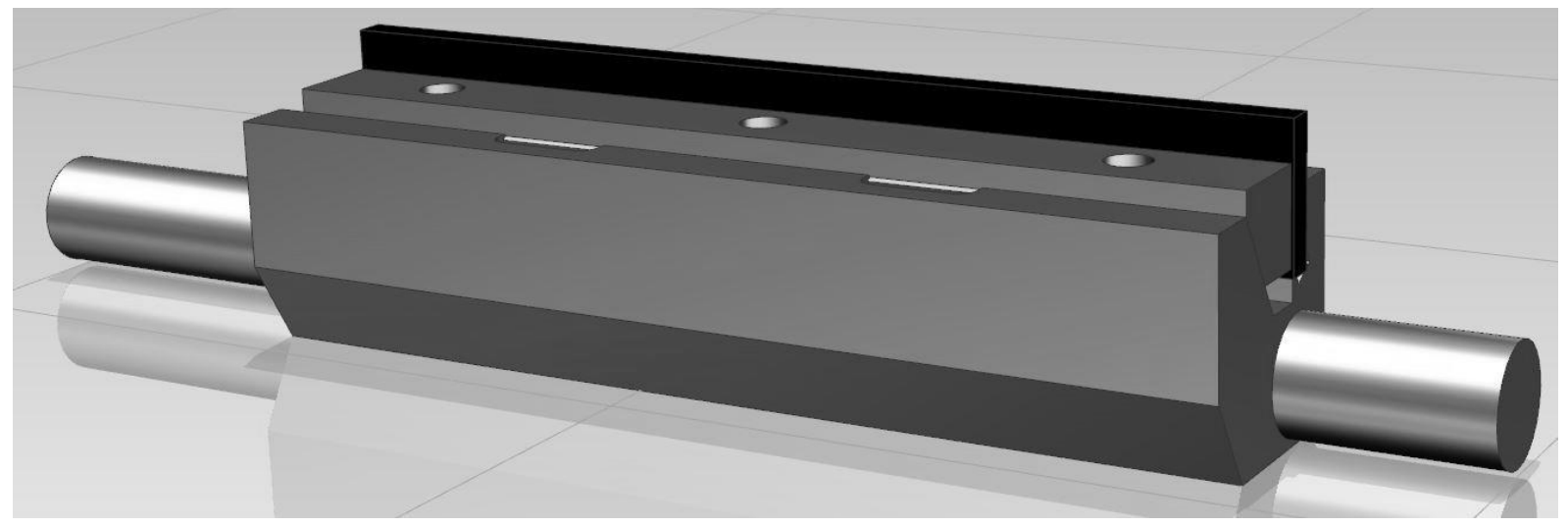

Fig. 2. The clamping rig with the test specimen

The experiments measure the changing forces as the grinding parameters are changed. Grinding speed $v_{c}$ and depth of cut $a_{e}$ were selected as the grinding parameter variables. The third variable was the type of grinding wheel. The feed rate of $200 \mathrm{~mm} \cdot \mathrm{min}^{-1}$ is constant for all the experiments. All variables of the grinding conditions are shown in Table 4 . with the designation of each experiment. Each experiment was done three times under the same conditions. The designation for the experiments in the results is always the designation of the grinding wheel plus the designation of the variables of the grinding conditions.

\begin{tabular}{|c|c|c|c|c|c|c|c|c|}
\hline Designation & $\mathrm{vc}_{\mathrm{c}}\left[\mathrm{m} \cdot \mathrm{s}^{-1}\right]$ & $\mathbf{a e}[\mathrm{mm}]$ & Designation & $v_{c}\left[m_{\cdot} s^{-1}\right]$ & $\mathbf{a e}_{\mathrm{e}}[\mathrm{mm}]$ & Designation & $\mathrm{vc}_{\mathrm{c}}\left[\mathrm{m} \cdot \mathrm{s}^{-1}\right]$ & $\mathrm{ae}[\mathrm{mm}]$ \\
\hline Exp01 & 10 & 0.05 & Exp04 & 10 & 0.1 & Exp07 & 10 & 0.2 \\
\hline Exp02 & 15 & 0.05 & Exp05 & 15 & 0.1 & Exp08 & 15 & 0.2 \\
\hline Exp03 & 20 & 0.05 & Exp06 & 20 & 0.1 & Exp09 & 20 & 0.2 \\
\hline
\end{tabular}

Table 4. Variables from grinding conditions

\section{Results}

As mentioned in the introduction, this work is focused on the measurement of the forces when changing grinding wheels and grinding parameters. Because the machine can only measure spindle load, it is necessary to recalculate the measured values from percent spindle load to forces. Equation (1) is used to recalculate the values.

$$
\begin{array}{rlll}
P=M \cdot \omega ; M=F & r ; & \omega=2 \cdot \pi \cdot n=>F=\frac{P \cdot p_{p}}{2 \cdot 100 \cdot \pi \cdot n \cdot r}[N] \\
\text { Where: } & & & \\
\mathrm{P} & \ldots & \text { Spindle performance } & {[\mathrm{W}]} \\
\mathrm{p}_{\mathrm{p}} & \ldots & \text { Percentage of spindle load } & {[\%]} \\
\mathrm{F} & \ldots & \text { Grinding force } & {[\mathrm{N}]} \\
\mathrm{M} & \ldots & \text { Torque } & {[\mathrm{Nm}]} \\
\mathrm{r} & \ldots & \text { Grinding wheel radius } & {[\mathrm{m}]} \\
\mathrm{n} & \ldots & \text { Revolutions } & {[\mathrm{rpm}]} \\
\omega & \ldots & \text { Angular speed } & {\left[\mathrm{rad} . \mathrm{sec}^{-1}\right]}
\end{array}
$$

Also, it is necessary to subtract the load from the grinding wheel which originates from centrifugal force. This centrifugal force is different for each grinding wheel and grinding speed. The values of these forces are shown in Table 5. The recalculated values are shown in Graph 1.

\begin{tabular}{|l|c|c|c|}
\hline \multirow{2}{*}{ Grinding Wheel } & Exp01, Exp04, Exp07 & Exp02, Exp05, Exp08 & Exp03, Exp06, Exp09 \\
\cline { 2 - 4 } & Load [\%] & Load [\%] & Load [\%] \\
\hline SiC-01 & 2.00 & 2.80 & 3.55 \\
\hline SiC-02 & 1.90 & 2.55 & 3.15 \\
\hline
\end{tabular}

Table 5. Values of the load on grinding wheel without grinding 


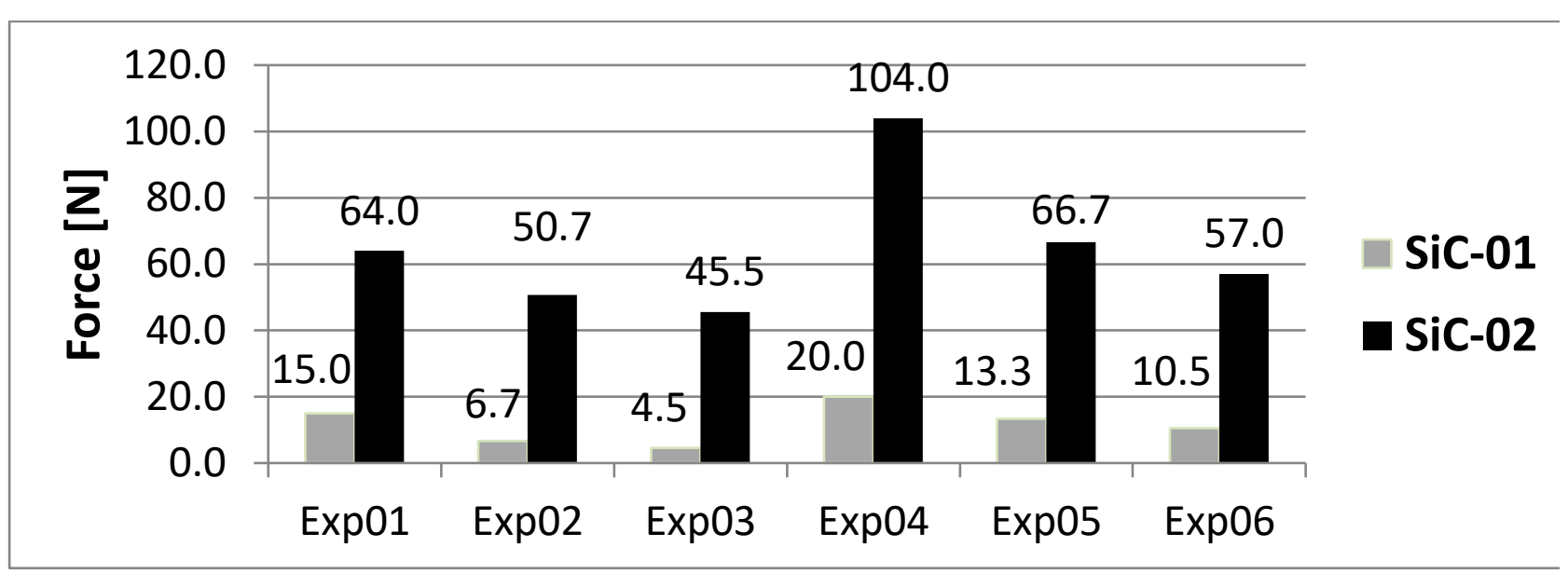

Graph 1. Values of forces on grinding

Only the values of experiments marked $01-06$ are shown in the graph because in these experiments the grinding was satisfactory without any damage to the surface. The changes in these experiments are very similar because the changes are linear. The linear change is shown in Fig. 3. Sometimes there are peaks when the force increases but in a moment drops back to a stable value, as seen in Fig. 4. These peaks are caused when the grinding wheel is recoated, because they appear only at the start of each new experiment.

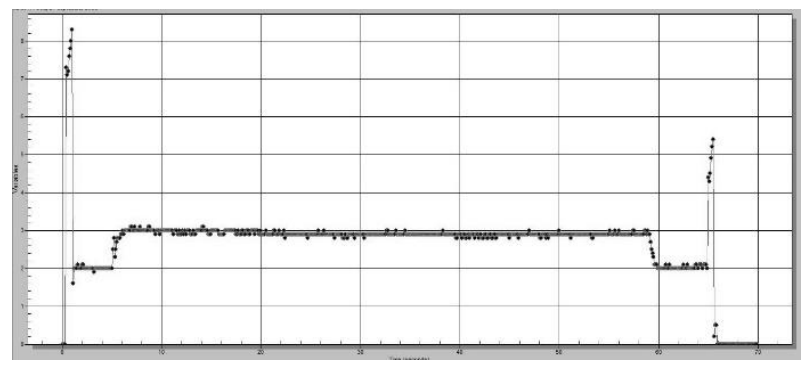

Fig. 3. The linear course of load

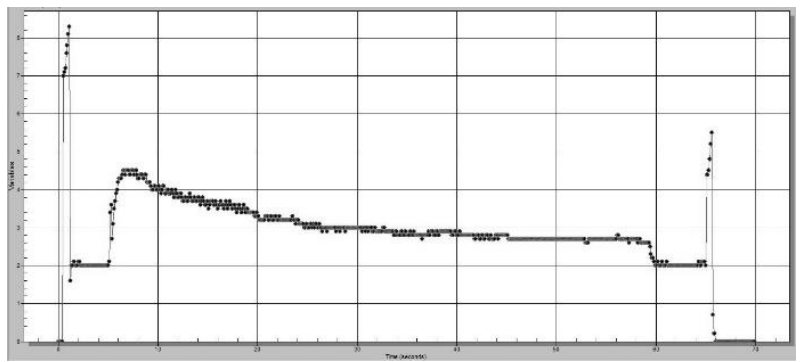

Fig. 4. The course of the load with start peak

As can be seen on the graph, the values of the grinding forces decrease when the grinding speed increases. But when the depth of the cut increases, the forces increase too. This factor can be very dangerous, because if the depth of the cut increases too much, then the surface of the material can be burned or damaged the grinding wheel. These values can be seen in these four figures. Fig. 5. shows the change of the load when the grinding wheel SiC-01 is damaged. The value of the forces was $160 \mathrm{~N}$ at a grinding speed of $10 \mathrm{~m} \cdot \mathrm{s}^{-1}$ and the depth of the cut was $0.2 \mathrm{~mm}$. In Fig. 6. you can see the course of the load when the grinding wheel Sic-02 was loosened by forces and stopped rotating. The force was $186 \mathrm{~N}$ under the same grinding parameters as the grinding wheel SiC-01 and was damaged. In the last two figures, you can see the course of the load when the surface was burned. Fig. 7. shows the load for the grinding wheel SiC-01 with value of force 108.5 $\mathrm{N}$, and Fig. 8. shows the load for SiC-02 with value of force $144.5 \mathrm{~N}$. Grinding parameters for both grinding wheels were the same and the value of the grinding speed was $20 \mathrm{~m} \cdot \mathrm{s}^{-1}$ and depth of cut $0.2 \mathrm{~mm}$. Because the results of experiments 7 and 9 were wrong, experiment 8 was not done, as a similar result was expected.

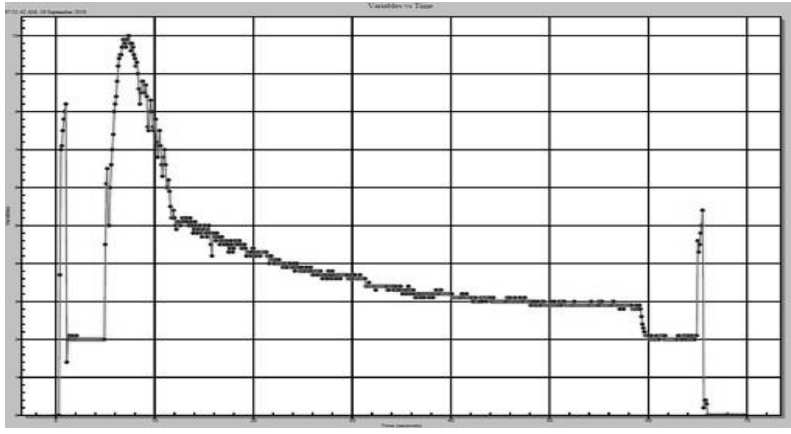

Fig. 5. SiC-01-Exp07

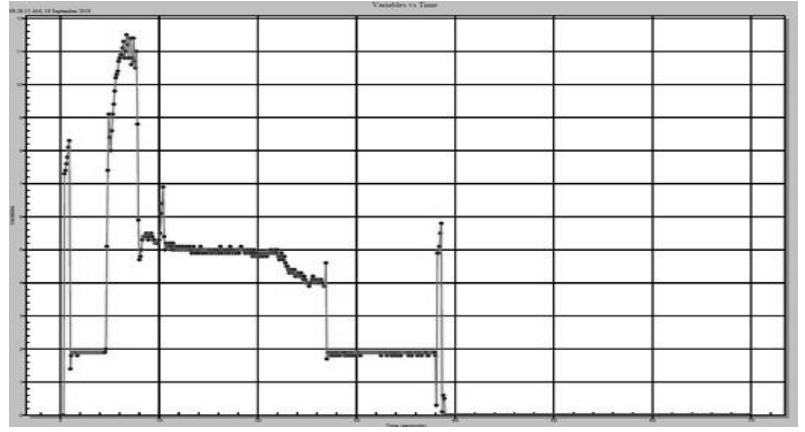

Fig. 6. SiC-02-Exp07 


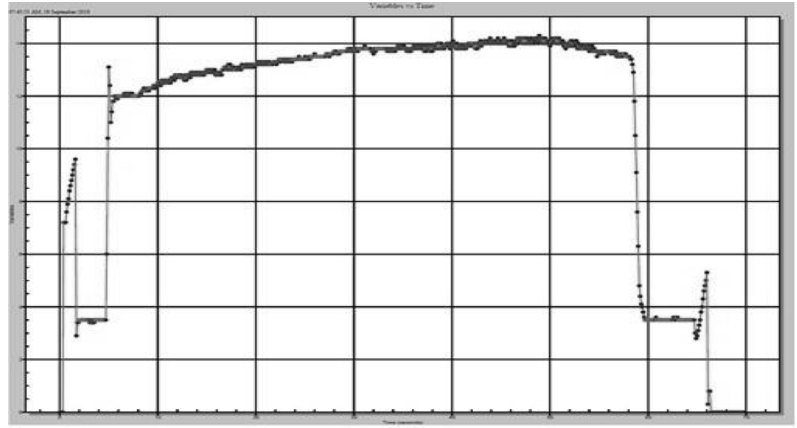

Fig. 7. SiC-01-Exp09

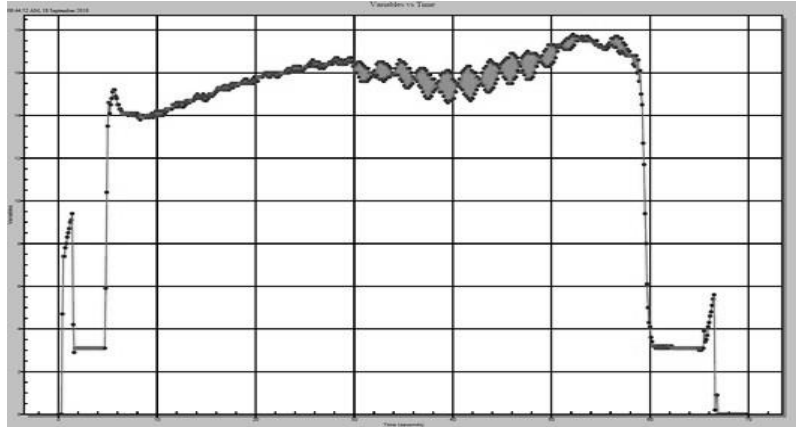

Fig. 8. SiC-02-Exp09

\section{Conclusion}

The issues of grinding forces are very complicated because there are many variables, which can be influenced by, or can influence, the other values. Therefore, it is necessary to monitor the changing forces because they can predict some characteristics and they can influence the future life of the components or the grinding wheels. These include for example the integrity of the surface, the residual stress, the wear on the grinding wheel, and so on.

This article shows only the basic results of the experiments when the variables were the grinding speed and depth of cut on two different grinding wheels with $\mathrm{SiC}$ abrasives. The results of these experiments show the basic changes to the forces on the grinding wheel which can influence the wear and the surface quality. In experiments 1 - 6 the changing forces were normal but for experiments 7 and 9 the forces showed extremes. These extremes predict some damage to the surface or the grinding wheel. These extremes have a very similar pattern, where the value of the force increases very fast and then the size of the forces either decreases very rapidly or increases slowly.

This experiment provides the basis for future research of the grindability of maraging steel X3NiCoMo 1895 using grinding wheels with $\mathrm{SiC}$ abrasives. This article focuses only on the forces which arise from grinding, but from the results it is evident that it is necessary to focus and observe the changes to the grinding forces because they can predict some states which can influence the future life of components and the grinding wheel.

\section{Acknowledgments}

This paper was supported by the Internal Grant Agency of the University of West Bohemia, project No. SGS-2016-005.

\section{References}

[1] Klocke, F. (2009). Manufacturing Processes 2: Grinding, Honing, Lapping. Springer Science \& Business Media ISBN 978-3-540-92259-9.

[2] Badger, J. A.; \& Torrance, A. A. (2000). 'A comparison of two models to predict grinding forces from wheel surface topography', International Journal of Machine Tools and Manufacture, ISSN 0890-6955, vol. 40, no. 8, pp. 10991120.

[3] Zhang, Y. et al. (2017). 'Analysis of grinding mechanics and improved predictive force model based on materialremoval and plastic-stacking mechanisms', International Journal of Machine Tools and Manufacture, ISSN 08906955, vol. 122, pp. 81-97.

[4] Fritsche, A. \& Bleicher, F. (2015). 'Experimental investigation of the heat flux distribution in grinding of titanium alloy', presented at the Procedia Engineering, ISSN 18777058, vol. 100, pp. 987-993.

[5] Baksa, T.; Hronek, O.; Farsky, J. \& Zetek, M. (2017). 'Influence of cutting conditions on the surface quality and grinding wheel wear during cylindrical grinding of inconel 718', presented at the Annals of DAAAM and Proceedings of the International DAAAM Symposium, ISBN 978-390273411-2, pp. 500-505.

[6] Baksa, T.; Farsky, J.; Hronek, O. \& Zetek, M. (2018). 'Influence of depth of cut on quality of ground surface and cutting force when grinding cermet', Manufacturing Technology, ISSN 12132489, vol. 18, no. 3, pp. 352-356.

[7] Farský, J.; Zetek, M.; Bakša, T. \& Adámek, P. (2017). 'Influence of grinding conditions on surface quality and accuracy when a tool grinder is used', presented at the Annals of DAAAM and Proceedings of the International DAAAM Symposium, ISBN 978-390273411-2 pp. 930-936.

[8] Dubovska, R.; Jambor, J. \& Majerik, J. (2014). 'Qualitative Aspects of Machined Surfaces of High Strength Steels', Procedia Engineering, ISSN 1877-7058, vol. 69, no. Supplement C, pp. 646-654.

[9] Bolzano, 'DataSheet of maraging steel X3NiCoMo 189 5', Bolzano. [Online]. Available: https://www.bolzano.cz/assets/files/materialove_listy/Vaco\%20180(1).pdf. . 